\title{
INFLUÊNCIA DOS PARÂMETROS DE CONFIGURAÇÃO DO MODELO CALMET SOBRE A SIMULAÇÃO DA CIRCULAÇÃO ATMOSFÉRICA NA REGIÃO METROPOLITANA DO RIO DE JANEIRO
}

\author{
LUIZ CLAUDIO GOMES PIMENTEL ${ }^{1}$, EDUARDO BARBOSA CORREIA ${ }^{2}$, EDILSON MARTON ${ }^{1}$, \\ MARCIO CATALDI ${ }^{3}$, ELCIO NOGUEIRA ${ }^{4}$
}

${ }^{1}$ Universidade Federal do Rio de Janeiro (UFRJ), Departamento de Meteorologia, Rio de Janeiro, RJ, Brasil

${ }^{2}$ Operador Nacional do Sistema Elétrico, Rio de Janeiro, RJ, Brasil

${ }^{3}$ Universidade Federal Fluminense, Niterói, RJ, Brasil

${ }^{4}$ Universidade do Estado do Rio de Janeiro (UERJ), Rio de Janeiro, RJ, Brasil

pimente165@gmail.com, ebcorrea@gmail.com, marton.ufrj@gmail.com, marcio.cataldi@gmail.com, elcionogueira@hotmail.com

Recebido Novembro de 2013 - Aceito Maio de 2014

\begin{abstract}
RESUMO
O objetivo desse estudo é a analise dos efeitos dos parâmetros de configuração do modelo CALMET sobre a simulação da circulação atmosférica em superfície nas Bacias Aéreas I e III da Região Metropolitana do Rio de Janeiro (RMRJ). O estudo foi realizado para um período em que a RMRJ estava sob a atuação de um sistema de alta pressão, que não influenciou significativamente as circulações locais na região. A análise conjunta dos resultados indica que a melhor configuração para simulações do campo de vento na RMRJ com o sistema combinado de modelagem MM5/CALMET é obtida utilizando o valor de $10 \mathrm{~km}$ para o parâmetro TERRAD e Raio de Influência entre 7 e $10 \mathrm{~km}$. Palavras-chave: Modelo diagnóstico, CALMET, circulação local, modelo de mesoescala, modelo prognóstico, MM5, qualidade do ar.
\end{abstract}

\begin{abstract}
INFLUENCE OF THE CONFIGURATION PARAMETERS OF THE CALMET MODEL ON THE SIMULATION OF THE ATMOSPHERIC CIRCULATION IN THE METROPOLITAN REGION OF RIO DE JANEIRO

The aim of this study is to analyze the effects of configuration parameters of the CALMET model on the simulation of atmospheric circulation over the surface at Air basins I and III on the Metropolitan Region of Rio de Janeiro (RMRJ). The study was conducted in a period when the RMRJ was under a high-pressure acting system, which not strongly influenced the local circulation over the region. The joint analysis of all results show that the best configuration for wind field simulations at the RMRJ, with the combined MM5/CALMET modeling is obtained using the value of $10 \mathrm{~km}$ for the TERRAD parameter and between 7 and $10 \mathrm{~km}$ for the influence radius.

Keywords: Diagnostic Model, CALMET, local circulation, mesoescale model, prognostic model, MM5, air quality.
\end{abstract}

\section{INTRODUÇÃO}

Como metodologia de controle das emissões atmosféricas, pode-se adotar, de forma complementar, as técnicas de monitoramento e modelagem da qualidade do ar, objetivando avaliar os níveis de concentração de poluentes e as possíveis violações a partir da comparação com os níveis de referência, conhecidos como padrões de qualidade do ar.

A modelagem atmosférica esteve direcionada em seu início para o desenvolvimento e aprimoramento de modelos prognósticos do tempo, área em que ocupou a atenção da comunidade científica. No entanto, nas últimas duas décadas 
ficou evidente que a modelagem atmosférica teria que incorporar os processos físico-químicos que ocorrem na atmosfera (Arndt et al., 1998). Isto não obedecia apenas a um interesse puramente acadêmico de entendimento do sistema atmosférico, senão a evidência crescente de que as atividades veiculares, industriais, agrícolas e de outro tipo estavam afetando o meio ambiente, com desdobramentos na modificação do clima. $\mathrm{Na}$ atualidade, a modelagem atmosférica é uma ferramenta indispensável para o desenvolvimento e aplicação de programas de gestão ambiental com foco no desenvolvimento sustentável, desde a escala urbana ou local até a escala global, e no auxílio à tomada de decisões emergenciais em situações de vazamentos acidentais de gases tóxicos.

A utilização de modelos de qualidade do ar (MQAr) fornece uma valiosa ferramenta para a avaliação das emissões de poluentes provenientes de fontes de diferentes tipologias, que podem ser analisadas de acordo com o impacto das concentrações geradas por essas na superfície; previsão e análise da área de influência das instalações industriais em relação às suas emissões gasosas; avaliação do impacto pretérito e futuro das instalações industriais, possibilitando a utilização de técnicas de mitigação dos impactos e para o planejamento operacional e de implantação de novas fontes de emissão.

A deficiente rede de estações de qualidade do ar, aliada a intensa atividade industrial dos grandes centros urbanos torna a utilização dos MQAr uma importante ferramenta para a compreensão integrada dos mecanismos que atuam na dispersão dos contaminantes atmosféricos. No entanto, a confiabilidade nos resultados desses modelos é altamente dependente da representatividade da circulação atmosférica local, que está associada a disponibilidade das informações meteorológicas da região do estudo e a configuração do sistema computacional de modelagem atmosférica utilizado.

Vale destacar que em sua maioria a rede de estações meteorológicas de superfície e altitude dos grandes centros urbanos não apresenta uma distribuição espacial adequada à representação da influência dos sistemas atmosféricos de microescala, mesoescala e escala sinótica atuantes na região da análise. Nesse contexto a utilização conjunta de modelos meteorológicos diagnósticos e prognósticos tem se constituído em uma alternativa eficiente para a simulação das condições atmosféricas, suprindo em muitas situações, a carência de informações observacionais utilizadas na simulação dos mecanismos de dispersão de poluentes atmosféricos (Chandrasekar et al., 2003; Jackson et al., 2006).

O Sistema acoplado de modelagem, composto pelo modelo prognóstico MM5 em conjunto com o modelo diagnóstico CALMET, têm sido aplicado frequentemente em regiões onde a dispersão de poluentes é fortemente influenciada pela complexidade da topografia, presença de corpos d'água e ocorrência de ventos de baixa intensidade ou calmaria (Earth Tech, 2005). Barna et al. (2000) e Barna e Lamb (2000) realizaram estudos na região da Cascadia, noroeste dos EUA, para verificar a melhor configuração de utilização do sistema combinado de modelos MM5/CALMET com o modelo fotoquímico CALGRID (Yamartino et al., 1992). A partir de diversas análises com diferentes configurações de simulação, os autores concluíram que os resultados mais satisfatórios foram obtidos a partir das simulações com o sistema combinado MM5/CALMET e assimilação de dados das estações meteorológicas. Chandrasekar et al. (2003) em um estudo similar com o acoplamento MM5/CALMET e o modelo fotoquímico Community Multiscale Air Quality - CMAQ (USEPA, 1999), obtiveram as mesmas conclusões obtidas por Barna et al. (2000) e Barna e Lamb (2000). Segundo os autores, as diferentes resoluções espaciais dos domínios do modelo MM5 não causaram diferenças significativas nos campos de vento calculados pelo modelo CALMET, provavelmente devido a pouca complexidade do terreno onde foi realizado o estudo. Earth Tech (2005) conduziu um estudo de sensibilidade com o sistema combinado de modelos MM5/CALMET. Os resultados do campo de vento obtidos com as diferentes configurações indicaram resultados similares e mostraram forte concordância com os dados observados da região de estudo. Jackson et al. (2006) realizaram estudos de dispersão de ozônio em uma região da Califórnia utilizando dois conjuntos de simulações, uma apenas com o modelo MM5 e a outra utilizando os dados simulados pelo modelo MM5 como campo de vento inicial com uma posterior correção, com o modelo diagnóstico CALMET. Os autores verificaram que os resultados foram fortemente influenciados pela presença de estações observacionais, e que as simulações realizadas com os modelos MM5 e CALMET foram mais coerentes com os dados observados do que os resultados obtidos apenas com o modelo MM5. Wang et al. (2008) utilizaram a combinação de modelos MM5 e CALMET para estudar o escoamento local em uma região de Chicago, cujas características são influenciadas pela presença de brisas lacustres. Os autores realizaram testes de sensibilidade com o modelo CALMET, para verificar a influência da quantidade de estações de dados observacionais assimilados, os impactos causados nos resultados pela modificação dos parâmetros de ajuste R (raio de influência dos dados da estação assimilada) e BIAS (peso dado aos dados de superfície e altitude durante a interpolação) disponíveis no modelo CALMET. A parametrização de brisa de lago e o ajuste de velocidade vertical através do procedimento de O'Brien (O'Brien, 1970) foram testadas. Segundo os autores os resultados do modelo CALMET, para a região de estudo mostraram-se coerentes com os dados observados da região, principalmente para o vento horizontal. Os autores afirmaram que os resultados foram mais 
influenciados pela distribuição e quantidade de estações de dados assimilados do que pelas diferentes configurações adotadas no modelo CALMET. A parametrização de O'Brien não trouxe melhorias aos resultados e aumentou consideravelmente o custo computacional da simulação, o mesmo ocorrendo com a ativação da parametrização de brisa de lago disponibilizada no modelo CALMET. Yim et al. (2007) realizaram estudos do potencial energético do campo de vento em Hong Kong, acoplando os modelos MM5 e CALMET. A verificação dos resultados foi realizada através da comparação com dados de três estações de superfície, uma de altitude e perfis verticais de vento até $2000 \mathrm{~m}$ medidos com um perfilador. Segundo os autores o domínio de maior resolução do CALMET representou de forma coerente os detalhes da topografia complexa da região, o que levou a melhores resultados dos campos de vento. Os autores ressaltaram a importância de se utilizar o modelo atmosférico MM5 em conjunto com o modelo CALMET, em virtude das simulações com o modelo diagnóstico serem bastante influenciadas pela frequência de dados meteorológicos, distribuição espacial de rede de monitoramento e qualidade das observações existentes na região de estudo.

A Região Metropolitana do Rio de Janeiro (RMRJ) é um grande centro urbano que se encontra submetido a sistemas meteorológicos nas mais variadas escalas espaçotemporais, tais como: ciclones e anticiclones transientes, Alta Subtropical do Atlântico Sul (ASAS), Zona de Convergência do Atlântico Sul (ZCAS), sistemas convectivos de mesoescala, tempestades convectivas localizadas e sistema de brisas terramar e de vale-montanha. Estudos anteriores verificaram que as condições meteorológicas na RMRJ influenciam fortemente as concentrações de poluentes prejudiciais à saúde, como material particulado e ozônio, inclusive com o escoamento transportando esses poluentes para locais distantes das fontes (Carvalho, 2004). As características fisiográficas da região aliada a sua importância sócio econômica e marcante situação de degradação ambiental, devido a crescente industrialização e malha viária, são fatores que justificam o desenvolvimento de sistemas computacionais adequados para a simulação integrada dos mecanismos de transporte na região.

Nesse sentido, o objetivo desse estudo é analisar a influência dos parâmetros de configuração do modelo CALMET, sobre os resultados de simulações do campo de vento em superfície nas Bacias Aéreas I e III da Região Metropolitana do Rio de Janeiro (RMRJ).

\section{DESCRIÇÃO DOS MODELOS MM5 E CALMET}

O modelo prognóstico de mesoescala MM5 é utilizado para a simulação dos campos de vento que são inseridos no modelo diagnóstico CALMET, para em conjunto com parametrizações físicas e interpoladores matemáticos disponíveis nesse modelo, serem estimados os parâmetros micrometeorológicos e o campo de vento do local do estudo, que serão disponibilizados para inserção em modelos de qualidade do ar.

\subsection{Modelo prognóstico de mesoescala MM5}

O Sistema MM5 é um modelo de simulação numérica desenvolvido no final da década de 70 pela Penn State University, em conjunto com o National Center for Atmospheric Research (NCAR). Atualmente, se encontra na 5a. geração e ao longo dos anos foram sendo incorporadas diversas modificações, como capacidade de múltiplos aninhamentos, dinâmica não hidrostática e assimilação de dados em 4 dimensões, além de várias parametrizações físicas e portabilidade em diversas plataformas computacionais. Utiliza um sistema de coordenadas que segue a topografia e resolve a equação da continuidade, as equações de Navier-Stokes em três dimensões, a $1^{a}$. Lei da Termodinâmica e a equação de transferência radiativa. Como todo modelo de área limitada, são necessárias condições iniciais e de contorno. No MM5 todas as 4 fronteiras possuem campos de ventos horizontais, temperatura e umidade especificados. Estes dados podem vir de analises de modelos de grande escala, simulações prévias do próprio MM5 ou de outro modelo prognóstico. O sistema MM5 possui uma estrutura modular composta por alguns programas auxiliares, responsáveis pela geração de informações necessárias para a simulação: TERRAIN, REGRID, little_r e INTERPF. O processamento dos dados e obtenção das previsões é feito pelo módulo MM5 e o pós-processamento, ou seja, a visualização dos resultados obtidos pode ser feita por vários programas, entre os quais, o GRADS. Maiores informações e descrição detalhada do modelo pode ser obtida em Grell et al. (1995).

\subsection{Modelo diagnóstico CALMET}

O Californian Meteorological Model (CALMET) faz parte do sistema de modelagem Californian Puff Model (CALPUFF), desenvolvido originalmente por Sigma Research Corporation (atualmente parte da Earth Tech, Inc.), como parte de um sistema de qualidade do ar para uso regulatório (Scire, 2000). O CALMET faz parte do conjunto de modelos conhecido como modelos de consistência de massa, baseados na equação da continuidade, que calculam campos de vento em uma malha tridimensional, sendo composto por dois módulos: diagnóstico do campo de vento e micrometeorológico. $\mathrm{O}$ módulo gerador de campos de vento diagnósticos é baseado em técnicas de análise objetiva e parametrizações que computam os efeitos cinemáticos e de bloqueio do terreno, e o escoamento em encostas. Também possui um procedimento de minimização 
da divergência do campo de velocidades. O modelo CALMET tem sido frequentemente utilizado em conjunto com modelos meteorológicos prognósticos, como o MM5, para estudos de dispersão e impacto ambiental. O módulo de vento diagnóstico utiliza um processo de duas etapas para o cálculo do campo de vento, baseado na formulação de Douglas e Kessler (1988). $\mathrm{Na}$ primeira etapa é fornecido um campo de vento inicial, variando espacialmente, que pode ser calculado com dados meteorológicos observados e interpolados utilizando análises objetivas, para preencher todo o domínio do CALMET, ou através da assimilação de resultados prognósticos de campos de vento originados de modelos atmosféricos de mesoescala como o MM5. O campo de vento inicial é então ajustado para levar em consideração os efeitos cinemáticos e de bloqueio devido ao terreno, e os escoamentos em encostas, gerando um campo de vento chamado Campo de Vento do Passo 1. Na segunda etapa, caso o campo de vento inicial tenha sido gerado a partir de dados prognósticos, é possível introduzir dados observados no Campo de Vento do Passo 1, submetendo-o ao mesmo procedimento de interpolação citado anteriormente, onde os dados próximos às estações meteorológicas recebem um peso maior, e os locais onde não existem estações meteorológicas permanecem com os dados gerados pelo Campo de Vento do Passo 1. Além do processo de interpolação, o campo de vento na segunda etapa também sofre ajustes através de processos de suavização, ajuste opcional das velocidades verticais e processo de minimização da divergência. Ao final da segunda etapa, é obtido o campo de vento final do modelo CALMET.

\section{MATERIAL E MÉTODOS}

\subsection{Configuração do sistema de modelagem MM5/ CALMET}

O MM5 foi inicializado com dados meteorológicos do modelo global GFS (Global Forecast System model) do National Centers for Environment Prediction (NCEP) com resolução espacial de $0,5^{\circ}$ de latitude/longitude $(\sim 55 \mathrm{~km})$ e resolução temporal de 3 horas, contendo informações necessárias para gerar as condições iniciais e de contorno. Todos os domínios do MM5 utilizaram as seguintes opções físicas: parametrização de cumulus proposta por Grell (Grell, 1993); parametrizações de microfísica de nuvens e radiação atmosférica (Dudhia, 1989); modelo de solo NOAH LSM (Chen e Dudhia, 2000) e parametrização de camada limite atmosférica (CLA) de Mellor e Yamada (1974). Foram utilizados quatro domínios, centralizados sobre a região do aeroporto internacional do Galeão (SBGL), com resoluções horizontais de $27 \mathrm{~km}, 9$ $\mathrm{km}, 3 \mathrm{~km}$ e $1 \mathrm{~km}$. Em todos os domínios foram utilizados dados de topografia e uso do solo do United State Geological
Survey (USGS - disponíveis em http://www.src.com/datasets/ datasets_terrain.html) com resoluções de $19 \mathrm{~km}, 9 \mathrm{~km}, 1 \mathrm{~km}$ e $1 \mathrm{~km}$, respectivamente. Foram utilizados 30 níveis na vertical se estendendo desde a superfície até aproximadamente 100 $\mathrm{hPa}$, que corresponde ao topo do domínio vertical, com maior detalhamento nos baixos níveis, perfazendo aproximadamente 15 níveis verticais até $850 \mathrm{hPa}$.

A inicialização do modelo CALMET foi feita com os resultados das simulações do domínio com $3 \mathrm{~km}$ de resolução horizontal do modelo MM5. Essa escolha foi o resultado da avaliação realizada comparando as intensidades do vento geradas pelo modelo CALMET, sendo inicializado com as simulações obtidas dos domínios de $1 \mathrm{~km}$ e $3 \mathrm{~km}$ do modelo MM5. Nessa análise verificou-se que não existiram diferenças significativas entre os resultados, concordante com outros estudos disponíveis na literatura (Prieto et al., 2007 e Earth Tech, 2005). A inicialização do CALMET foi complementada com a assimilação dos dados medidos em 23 estações meteorológicas de superfície, originadas da REDEMET (Rede de Meteorologia do Comando da Aeronáutica - www.redemet.aer.mil.br) e uma estação de altitude (bancodedados.cptec.inpe.br), distribuídas de acordo com a Figura 1, sendo a estação SBGL contabilizada como de superfície e também de altitude. A escolha da resolução espacial do modelo CALMET foi feita com base nos resultados de simulações utilizando as resoluções horizontais de $1 \mathrm{~km}$, 500 metros e 250 metros. Scire et al. (2000) recomendam a utilização da resolução espacial similar à da base de dados de uso do solo, ou seja, $1 \mathrm{~km}$ no estudo realizado. No entanto, devido à complexidade topográfica da RMRJ e a diversidade de configurações encontradas na literatura, decidiu-se por uma análise de sensibilidade. A análise dos resultados (não mostrada) levou a escolha da resolução espacial de $1 \mathrm{~km}$ para o domínio do CALMET, utilizando dados de topografia de 90 metros do banco de dados Shuttle Radar Topography Mission (SRTM) (disponíveis em http://www.src.com/datasets/datasets_terrain. html) e dados de uso do solo de $1 \mathrm{~km}$ da USGS.

Os diversos parâmetros físicos contidos no modelo CALMET, que influenciam os resultados do campo de vento, devem ser configurados de acordo com as particularidades da região de aplicação do modelo, como disponibilidade e densidade de estações meteorológicas, uso do solo e topografia (Wang et al., 2008). Sendo assim, neste trabalho foram verificados dois desses parâmetros, o TERRAD e o parâmetro $\mathrm{R}$, escolhidos por serem considerados de maior influência sobre a geração do campo de vento pelo CALMET (Scire et al. 2000).

O parâmetro TERRAD é utilizado no cálculo dos efeitos topográficos sobre o campo do vento, como as circulações de encosta e efeitos de bloqueio do escoamento. $\mathrm{O}$ valor atribuído ao TERRAD é utilizado pelo modelo CALMET para traçar um raio de ação em torno de cada ponto de grade, onde a elevação 


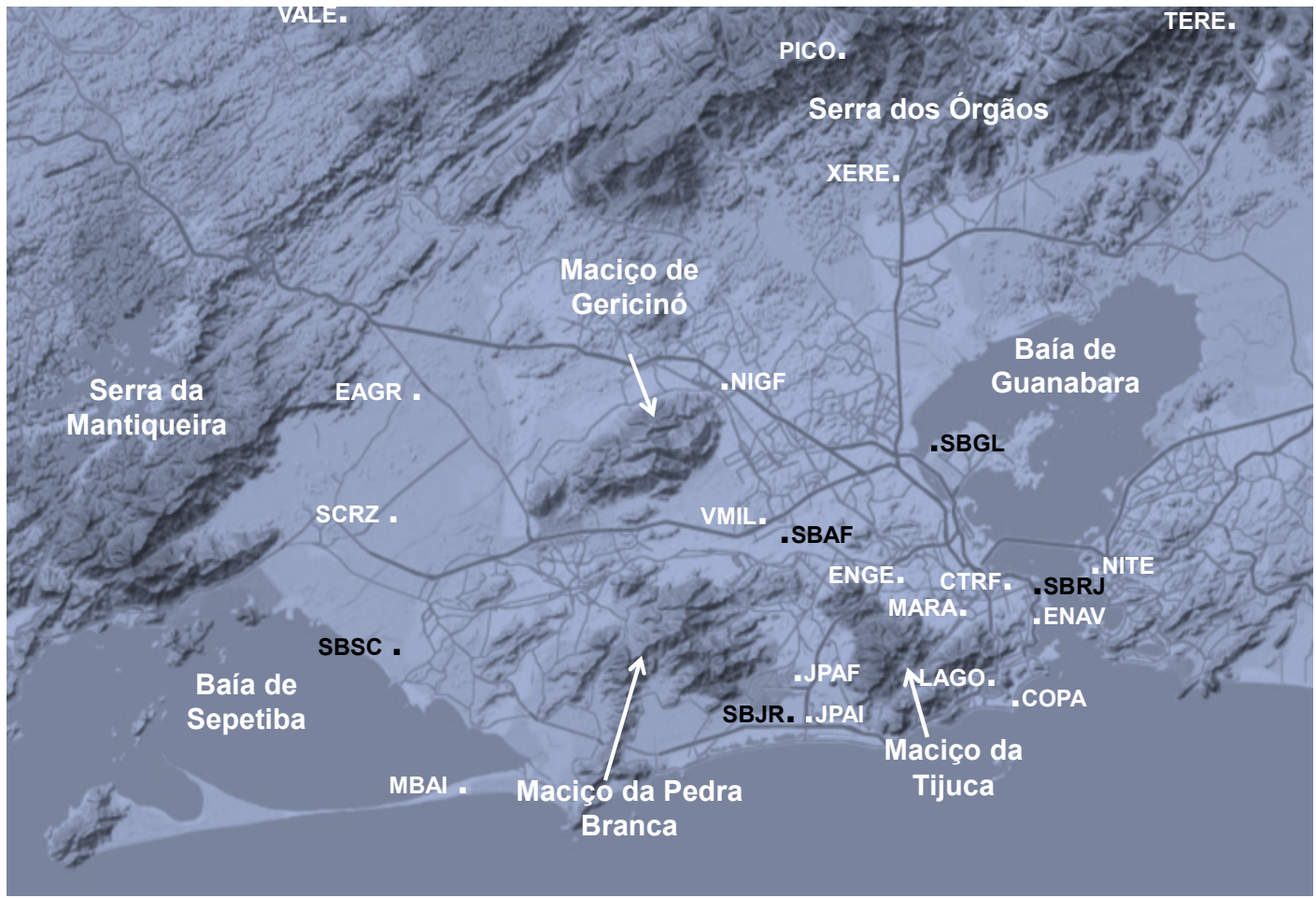

Figura 1 - Localização das estações meteorológicas assimiladas pelo modelo CALMET, bem como das principais características Geograficas da região em estudo.

do terreno é calculada considerando o ponto mais alto no interior desse raio. Scire et al. (2000) recomendam que seja utilizado um valor da ordem de 5 a 10 vezes a resolução horizontal utilizada no domínio do CALMET. Foram realizados testes de sensibilidade utilizando valores de $1 \mathrm{~km}$ e $10 \mathrm{~km}$ para o parâmetro TERRAD e verificou-se que a maior concordância entre os resultados das simulações e os dados observados nas estações meteorológicas foi para o valor do parâmetro TERRAD igual a $10 \mathrm{~km}$, sendo, portanto esse o valor escolhido para as simulações seguintes.

O parâmetro R é utilizado pelo modelo CALMET durante a segunda etapa da geração do campo de vento, quando ocorre a assimilação dos dados meteorológicos das estações. O valor informado nesse parâmetro é utilizado para calcular o peso que será atribuído aos dados meteorológicos e aos dados do modelo MM5 utilizados na primeira etapa, a partir da distância de cada estação meteorológica. Scire et al. (2000) recomendam que seja utilizado um valor da mesma ordem que a resolução espacial utilizada no modelo CALMET, mas devido à complexidade de terreno da RMRJ e a baixa densidade de estações meteorológicas de superfície e de altitude disponíveis para a região, optou-se por verificar melhor o funcionamento deste parâmetro utilizando os valores de 1,3, 7 e $10 \mathrm{~km}$. O critério adotado para a estimativa destes valores foi a avaliação da região em torno das estações, considerando a presença das principais forçantes das circulações na RMRJ, ou seja, os maciços topográficos e os corpos d'água, além da distância das estações avaliadas até essas forçantes. A análise dos resultados das simulações do CALMET é feita para a intensidade e direção do vento próximo à superfície, possibilitando a comparação com os dados meteorológicos das estações de superfície disponíveis na região.

\subsection{Período do estudo e críterio de avaliação dos resultados}

O estudo foi realizado durante o período de 4 a 8 de setembro de 2007, onde a análise sinótica demonstrou que, de modo geral, a região de estudo encontrava-se sob a influência da ASAS, posicionada aproximadamente em $30^{\circ} \mathrm{S} \mathrm{e} 30^{\circ} \mathrm{W}$. Este sistema de alta pressão permaneceu semi-estacionário durante os dias 4 a 7, contribuindo para inibição de nebulosidade e o avanço de sistemas frontais para latitudes mais baixas nesse período. A partir do dia 8, esse padrão de escala sinótica teve sua configuração alterada devido à passagem de um sistema frontal no oceano. A escolha de um período, sob influência da ASAS, ocorreu com o intuito de representar uma condição mais crítica para a dispersão de poluentes na atmosfera. A atuação da ASAS é uma das situações atmosféricas mais recorrentes no Rio de Janeiro (Reboita et al., 2010), ocasionando ventos normalmente no quadrante norte, variando entre nordeste e 
noroeste, de acordo com a posição do seu centro. Durante os meses do inverno austral os campos de vento tendem a ser, em média, mais intensos, mas mantendo ainda as mesmas direções predominantes (Bastos e Ferreira, 2000).

Normalmente, quando esta região está sob influência da ASAS, não há significativa influência na circulação local. Desta forma, acredita-se que um episódio sob influência da ASAS, assim como o ocorrido entre os dias de 4 a 8 de setembro de 2007, seja suficiente para retratar as condições adversas de dispersão de poluentes na atmosfera, que é um aspecto característico deste tipo de sistema.

A avaliação dos resultados das simulações foi realizada pontualmente através da análise da evolução horária de intensidade e direção do vento. Os resultados foram comparados com os dados observacionais de quatro estações meteorológicas de superfície para as Bacias Aéreas I e III, as quais são as áreas mais degradadas do ponto de vista de qualidade do ar na RMRJ. As estações consideradas nessa análise são as seguintes: estação do Aeroporto de Santa Cruz (SBSC), localizada na Bacia Aérea I e as estações instaladas nos Aeroportos de Afonsos (SBAF), do Galeão (SBGL) e de Santos Dumont (SBRJ), localizadas na Bacia Aérea III. A distribuição geográfica das estações pode ser observada na Figura 1.

\section{RESULTADOS}

Nas seções seguintes desse capítulo, são apresentados os resultados das simulações realizadas com o modelo CALMET para diferentes valores do raio de influência $R$. A intensidade e a direção do vento simulados para o período de 4 a 8 de setembro de 2007 são comparados com os dados registrados em estações de superfície, tomadas como referência nas Bacias Aéreas I (estação SBSC) e III (estações SBAF, SBRJ e SBGL).

\subsection{Análise dos resultados para a Bacia Aérea I}

A estação SBSC (Figura 1) localiza-se bem próxima à Baía de Sepetiba, cuja linha de costa possui orientação noroestesudeste em relação à estação. Ao sul encontra-se o Oceano Atlântico, a norte a Serra do Mar, destacando a norte/nordeste a Serra dos Órgãos. Pelo lado leste da estação encontra-se uma área urbanizada, referente aos bairros de Santa Cruz e Campo Grande na zona oeste da RMRJ. Segundo Pimentel et al. (2014), o regime de ventos nesta estação é caracterizado pelas direções sudoeste/nordeste, com predominância dos ventos de nordeste durante a madrugada e manhã e de sudoeste durante os períodos da tarde e noite. Esse regime de ventos sugere um forçamento térmico pelo mecanismo de brisa marítima/terrestre, devido à proximidade da estação SBSC da Baía de Sepetiba e do oceano. A região da Bacia Aérea I não possui muitas estações meteorológicas instaladas que possam auxiliar na avaliação do campo de vento. Além da estação SBSC, nessa região encontram-se instaladas as estações de Santa Cruz (SCRZ), Ecologia Agrícola (EAGR) e Marambaia (MBAI), estando a SCRZ dentro do raio de influência $R_{-} 10$ e as duas últimas fora do domínio desse raio.

Na Figura 2 são apresentados os dados observados e os resultados das simulações com o CALMET para a intensidade do vento na estação SBSC. As observações apresentam máximos valores de intensidade do vento em torno de $6-8 \mathrm{~m} / \mathrm{s}$ nos horários entre $1400 \mathrm{Z}$ e $1800 \mathrm{Z}$, exceto no dia 5 em que esse máximo é atingido às 1200Z. Esses valores máximos na intensidade do vento coincidem com o período de máximo desenvolvimento da brisa marítima nesse local, reportado por Pimentel et al. (2014). Verifica-se que os resultados das simulações R_7 e R_10 se aproximam mais do vento observado. A simulação R 3 também apresentou resultados semelhantes ao observado, com maiores discrepâncias no período madrugada/manhã. A configuração R_ 1 foi a que mais se distanciou do comportamento observado, simulando apenas alguns horários com sucesso.

$\mathrm{Na}$ Figura 3 são apresentados os resultados das simulações para a direção do vento em comparação com os dados observados para a estação SBSC (linha inferior da figura). Os dados observados indicam um ciclo diário de brisa no dia 4, com ventos de nordeste no período madrugada/ manhã e ventos de sudeste na tarde/noite, sendo, portanto, paralelo à linha de costa e não perpendicular, com se espera do padrão típico observado na região. Nos dias 5 e 6 os ventos são de nordeste, indicando o predomínio da escala sinótica (ventos provenientes da ASAS) sobre a escala local. Nos dias seguintes, 7 e 8, existe alternância na direção dos ventos, porém não exibindo claramente um padrão de brisa marítima/terrestre nos períodos típicos da tarde/noite e madrugada/manhã. É possível que mudanças nos ventos de escala sinótica em função de alterações na configuração da ASAS, decorrentes da passagem de sistema frontal no Oceano Atlântico no dia 8, tenham influenciado a circulação local. Apesar disso, ventos de nordeste, típicos da brisa terrestre em SBSC, são evidentes no final da manhã (em torno de 1200 Z), enquanto que são observados no período tarde/noite ventos de sudoeste (dia 7) e de sul (dia 8), referente à atuação da brisa marítima no local.

Todas as configurações usadas no modelo obtiveram sucesso em simular as direções do vento para os dias 4 a 6 . Para os dias 7 e 8 apenas a simulação $R_{-} 1$ não representou adequadamente o vento, indicando direções norte e nordeste na maior parte do período, de forma discrepante aos demais resultados (vento de sudoeste). Esse resultado pode ser atribuído à influência do campo de vento simulado pelo modelo MM5, utilizado para compor o vento no Passo 1 pelo modelo 

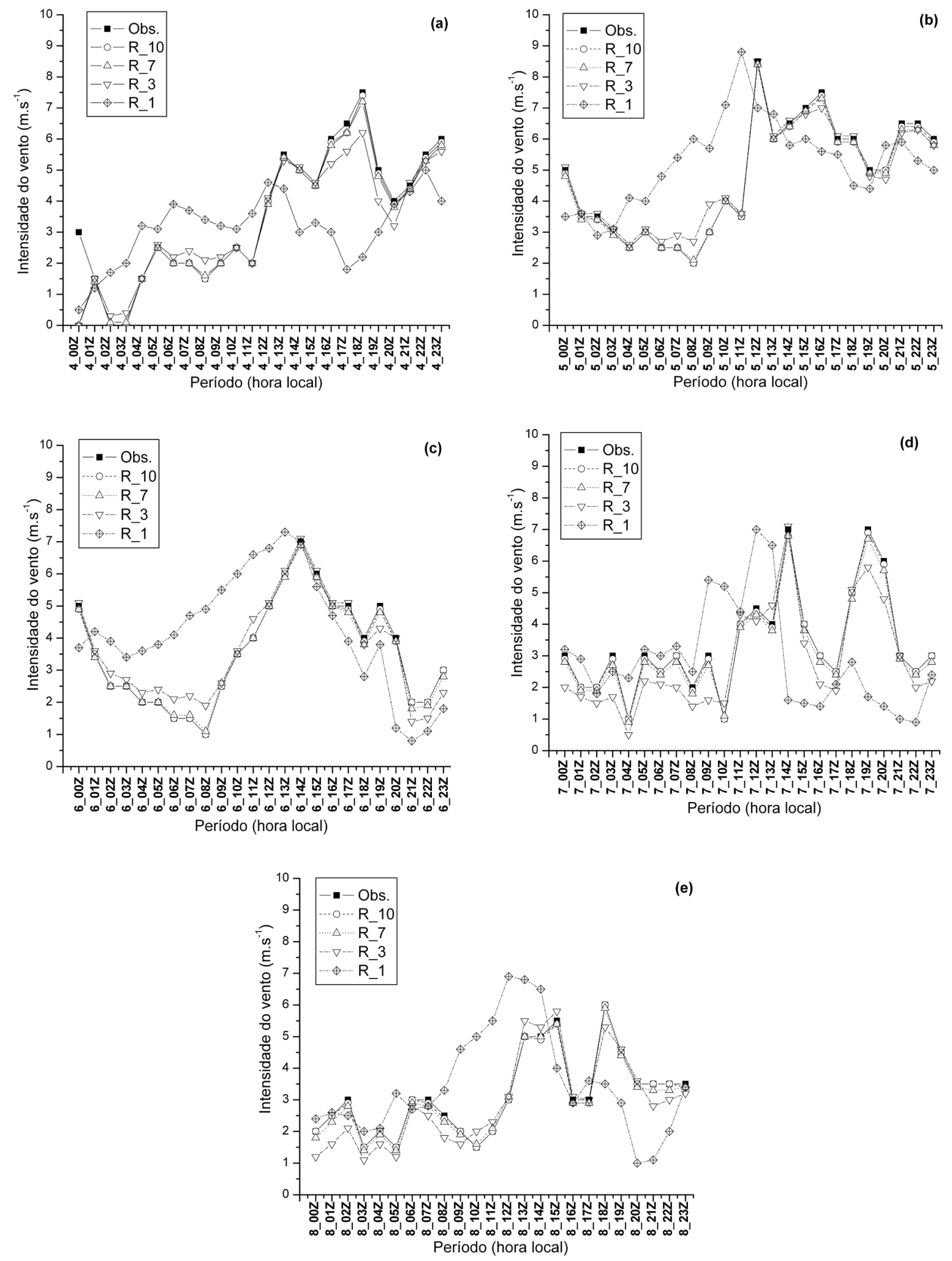

Figura 2 - Comparação da intensidade do vento, simulada pelo modelo CALMET, utilizando valores de $1 \mathrm{~km}, 3 \mathrm{~km}, 7 \mathrm{~km}$ e $10 \mathrm{~km}$ para R, e dados observados da estação SBSC para o período de 4 a 8 de setembro de 2007. 


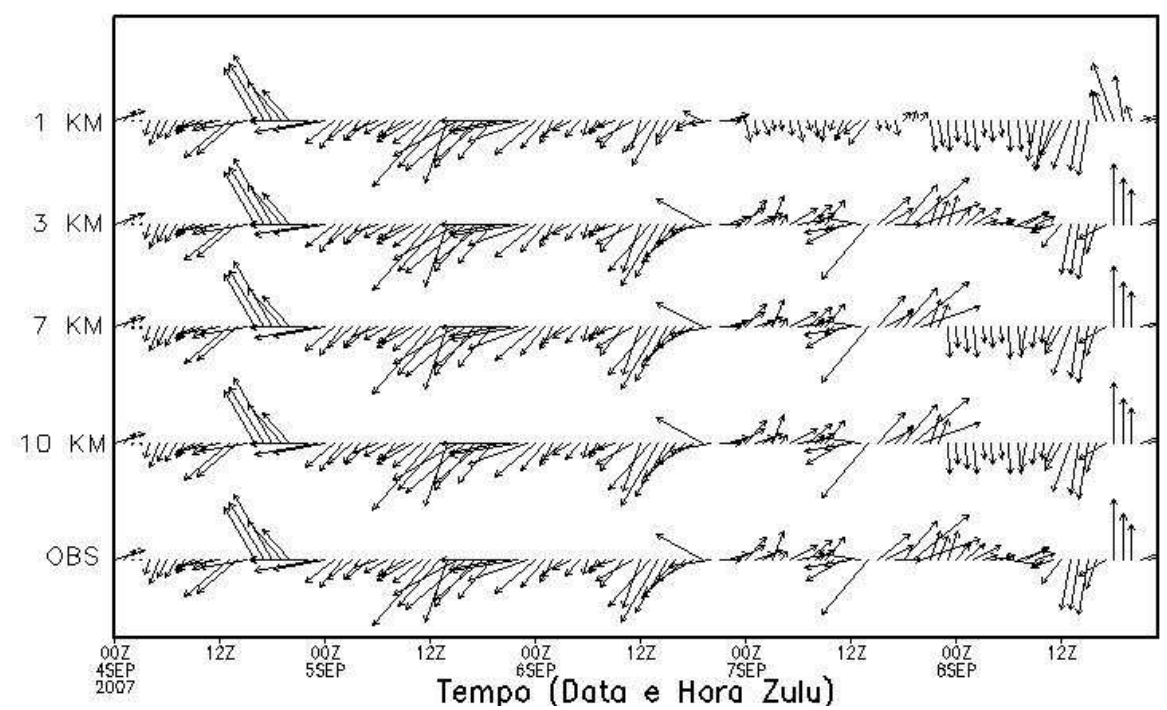

Figura 3 - Comparação da direção do vento simulada pelo modelo CALMET, utilizando valores para $\mathrm{R}$ com $1 \mathrm{~km}\left(\mathrm{R} \_1\right), 3 \mathrm{~km}(\mathrm{R}$ _ $), 7 \mathrm{~km}(\mathrm{R}$ 7) e 10 km (R_10), e dados observados da estação SBSC para o período de 4 a 8 de setembro de 2007.

CALMET, pois quando se utilizam valores pequenos nos raios de influência, aumenta-se proporcionalmente o peso do campo de vento calculado na primeira etapa. Isso evidencia que os resultados das simulações com o MM5, utilizados na construção do campo de vento na primeira etapa, apresentaram significativas discrepâncias em relação aos dados observados. Uma tendência inversa é identificada quando se aumenta o raio de influência, onde se observa que o campo de vento do Passo 2 é predominantemente construído a partir dos dados registrados nas estações de superfície mais próximas do ponto avaliado. Assim, como observado na Figura 3, as simulações $R \_3, R \_7$ e $R \_10$ obtêm maior sucesso em capturar as variações da direção do vento, pois se observa que elas acompanharam o comportamento do vento durante a maior parte do período, ao contrário da configuração $R_{-} l$ que se distanciou dos dados observados, principalmente nos horários de maior e menor intensidade do vento.

\subsection{Análise dos resultados para a Bacia Aérea III}

As estações SBAF, SBRJ e SBGL foram escolhidas para a verificação do vento simulado pelo CALMET na Bacia Aérea III.

A estação SBAF está localizada mais para o interior do continente, em uma área densamente urbanizada e rodeada pelos maciços do Mendanha, Pedra Branca e Tijuca (Figura 1). De acordo com Pimentel et al. (2014), os ventos nessa localidade são relativamente fracos, com direções distribuídas em vários quadrantes e elevados percentuais de calmaria, principalmente durante a madrugada. O período da manhã possui uma distribuição ampla de direções observadas e a parte da tarde é caracterizada por uma predominância bem definida da direção sul e poucos registros de calmaria. O período da noite apresenta predominância da direção sul e leste.

Em relação à avaliação do campo de vento simulado na estação SBAF, existem outras três estações dentro dos raios de influência utilizados nas simulações, as quais são denominadas JPAF, VMIL e ENGE. Essas três estações estão situadas respectivamente a sul, noroeste e a sudeste da estação de referência SBAF (Figura 1).

Na Figura 4 são apresentados os resultados das simulações para a intensidade do vento em SBAF e respectiva comparação com as observações registradas nessa estação. Os dados observados demonstram uma variação da intensidade do vento ao longo do período, com picos de 3,5-7,5 m/s entre os horários de $1600 \mathrm{Z}$ a $2000 \mathrm{Z}$ e ventos mais fracos e calmarias no período madrugada/manhã. A variação de intensidade observada nesta estação no período do estudo está em acordo com os resultados obtidos por Pimentel et al. (2014), que verificou ocorrência frequente de calmarias no período madrugada/ manhã, decorrentes da localização dessa estação, que se encontra rodeada pelos três maciços litorâneos da Tijuca, Pedra Branca e Mendanha.

Verifica-se que os resultados das diversas configurações das simulações subestimaram a intensidade do vento observado, com maior discrepância apontada para a configuração $R \_$. Como discutido nas análises anteriores, a configuração $R_{-} 1$ privilegia os resultados do modelo prognóstico na composição do vento final, indicando a inadequada representação do MM5 na simulação do campo de vento. As configurações $R_{-} 3 \mathrm{e}$ $R \_7$, utilizando a contribuição dos dados da estação VMIL, e 

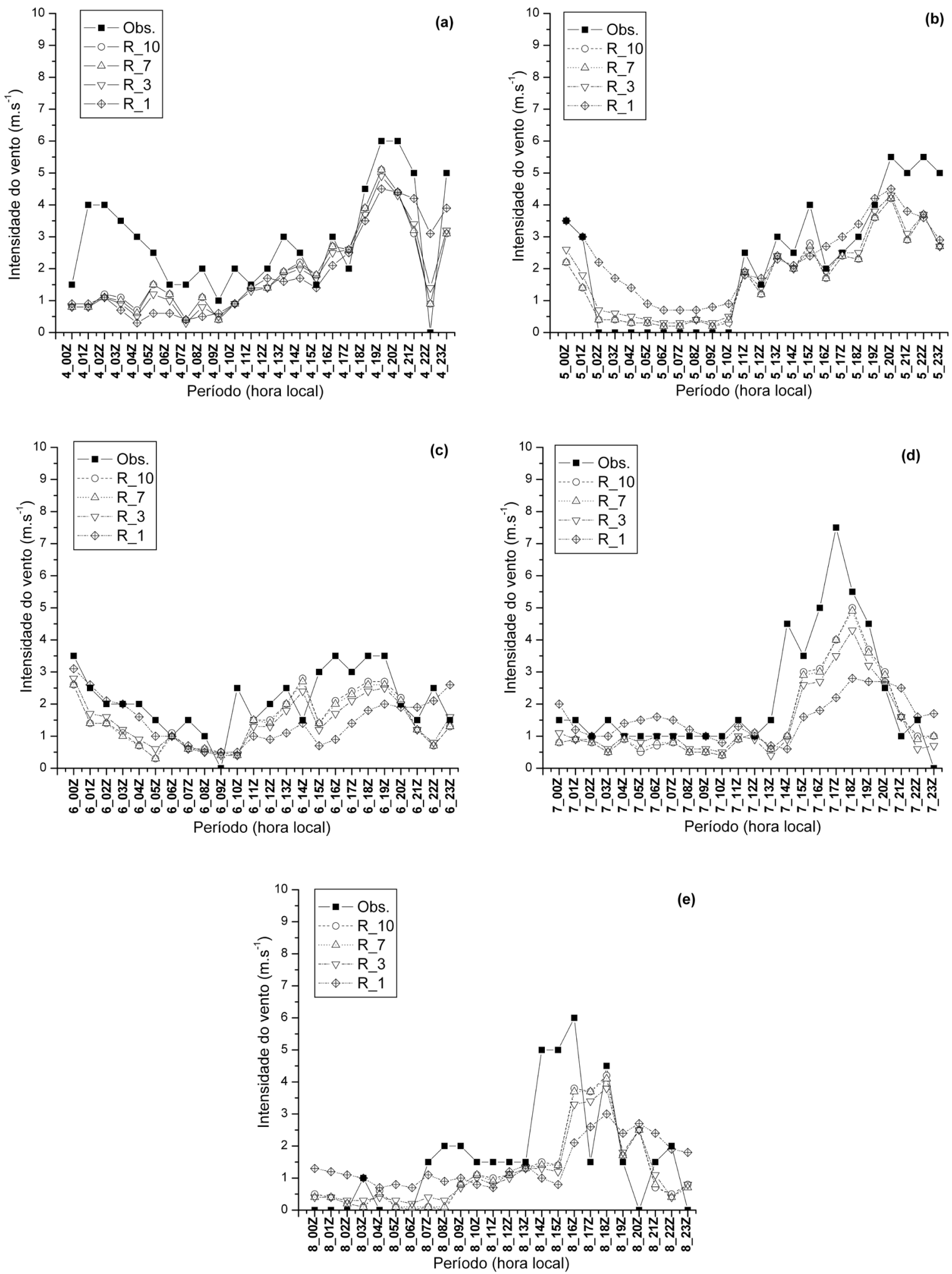

Figura 4 - Comparação entre intensidade do vento simulada pelo modelo CALMET, utilizando valores para R com $1 \mathrm{~km}, 3 \mathrm{~km}, 7 \mathrm{~km}$ e $10 \mathrm{~km}$, e dados observados da estação SBAF para o período de 4 a 8 de setembro de 2007. 
a configuração $R_{-} 10$, que inclui também os dados das estações JPAF e ENGE, subestimaram em menor grau a intensidade do vento.

A Figura 5 apresenta a direção dos ventos referente às simulações e aos dados observados em SBAF. Em relação aos dados observados, é possível verificar alguns períodos de calmaria na madrugada e ventos marcantes de sul no período da tarde, principalmente após $1200 \mathrm{Z}$ do dia 6 . É importante notar que esse vento de sul também foi verificado em localidades mais ao sul, como na estação SBJR (figura não mostrada), situada próxima à linha de costa. Essa configuração no padrão do vento sugere um efeito de canalização do escoamento desde o oceano, passando por entre os maciços da Pedra Branca e da Tijuca e atingindo a estação SBAF. Resultado este também observado em Pimentel et al. (2014). Esse efeito de canalização é um dos mecanismos dinâmicos de forçamento do escoamento próximo à superfície, que é conceitualmente discutido em Whiteman e Doran (1993), a partir de um estudo sobre a modificação da circulação local por efeito da topografia, em regiões de vale e do escoamento de escala sinótica em níveis da atmosfera logo acima.

Em relação aos resultados das simulações, algumas inconsistências na direção do vento podem ser notadas com o uso da configuração $R_{-} 1$ (Figura 5), principalmente nos três primeiros dias. Para os dois últimos dias houve uma melhor representação das direções, apesar das simulações mostrarem um padrão de sudoeste-sul enquanto as observações registraram sudeste-sul. As simulações $R \_3, R \_7$ e $R \_10$ representaram a variação do vento de forma similar entre si, e concordando em grande parte com os dados registrados na estação durante todo o período. A maior concordância obtida entre as simulações
$R \_3, R \_7$ e $R \_10$ é devido ao maior peso atribuído aos dados observados conforme se aumenta o raio de influência, como discutido nas análises anteriores.

A seguir procede-se a análise relativa à estação SBRJ, a qual se localiza na entrada da Baía da Guanabara, a norte da estação e com o oceano ao sul (Figura 1). As áreas vizinhas à estação SBRJ são densamente urbanizadas, apresentando pouca cobertura vegetal. De acordo com Pimentel et al. (2014), o vento local apresenta um padrão norte-sul evidente, sendo a direção sul (norte) predominante durante o período tarde/noite (madrugada/manhã) e calmaria quase inexistente.

As estações localizadas nas proximidades da SBRJ, cujos dados contribuíram para os campos de vento simulados são: estação Escola Naval (ENAV), localizada dentro do raio de 1 $\mathrm{Km}$; estações Centro (CTRF) e Niterói (NITE), distantes cerca de $3 \mathrm{Km}$ da SBRJ; estação Maracanã (MARA), localizada no raio de $7 \mathrm{Km}$; e estações Lagoa (LAGO) e Forte de Copacabana (COPA), no raio de $10 \mathrm{Km}$ da SBRJ. Dessa forma, a Figura 6 apresenta os resultados das simulações para a intensidade do vento e a comparação com os dados medidos na estação SBRJ. As observações mostram valores máximos de 6 a $7 \mathrm{~m} / \mathrm{s}$, ocorrendo aproximadamente entre as $1800 \mathrm{Z}$ e $2100 \mathrm{Z}$, e os mínimos durante o período madrugada/manhã.

De modo geral as simulações subestimaram significativamente os valores do vento observado. A simulação $R_{-} l$ foi a que mais se aproximou dos picos de intensidade registrados na estação, apesar de também subestimar a intensidade do vento na maioria do período. $\mathrm{Na}$ análise dos dados de intensidade do vento da estação ENAV (não apresentado), que se encontra no interior do raio

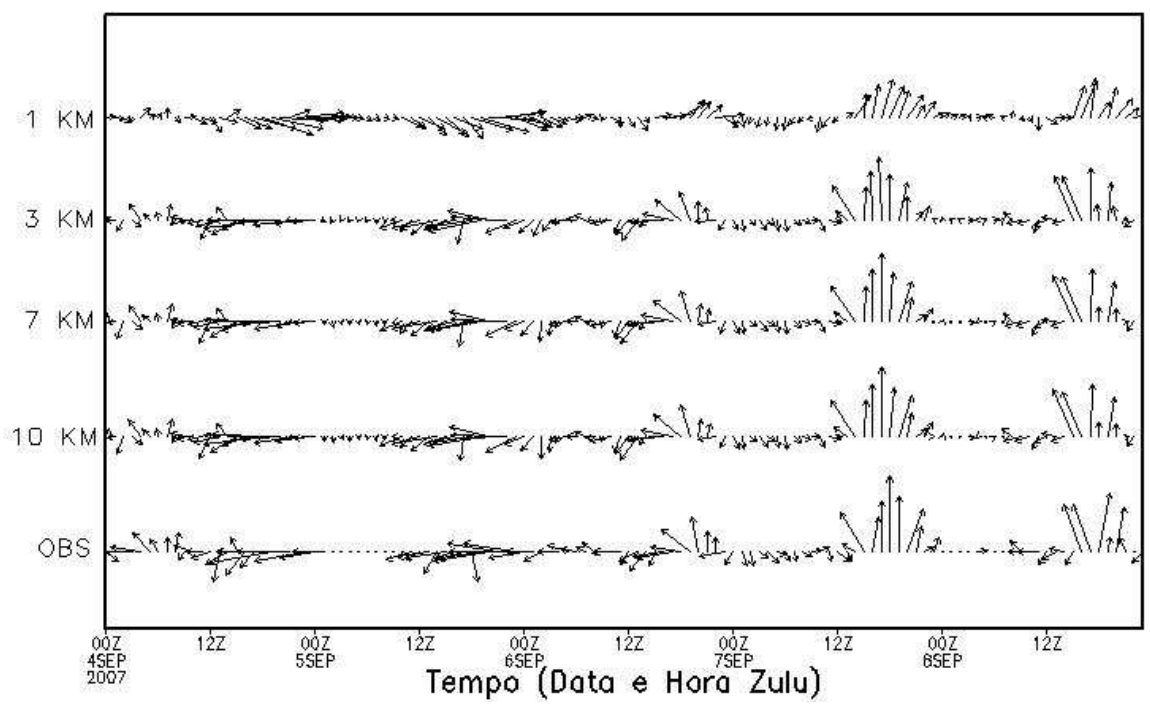

Figura 5 - Comparação entre a direção de vento, simulada pelo modelo CALMET, utilizando valores para R com 1 km (R_1), 3 km (R_3), 7 km (R_7) e 10 km (R_10), e dados observados da estação SBAF para o período de 4 a 8 de setembro de 2007. 

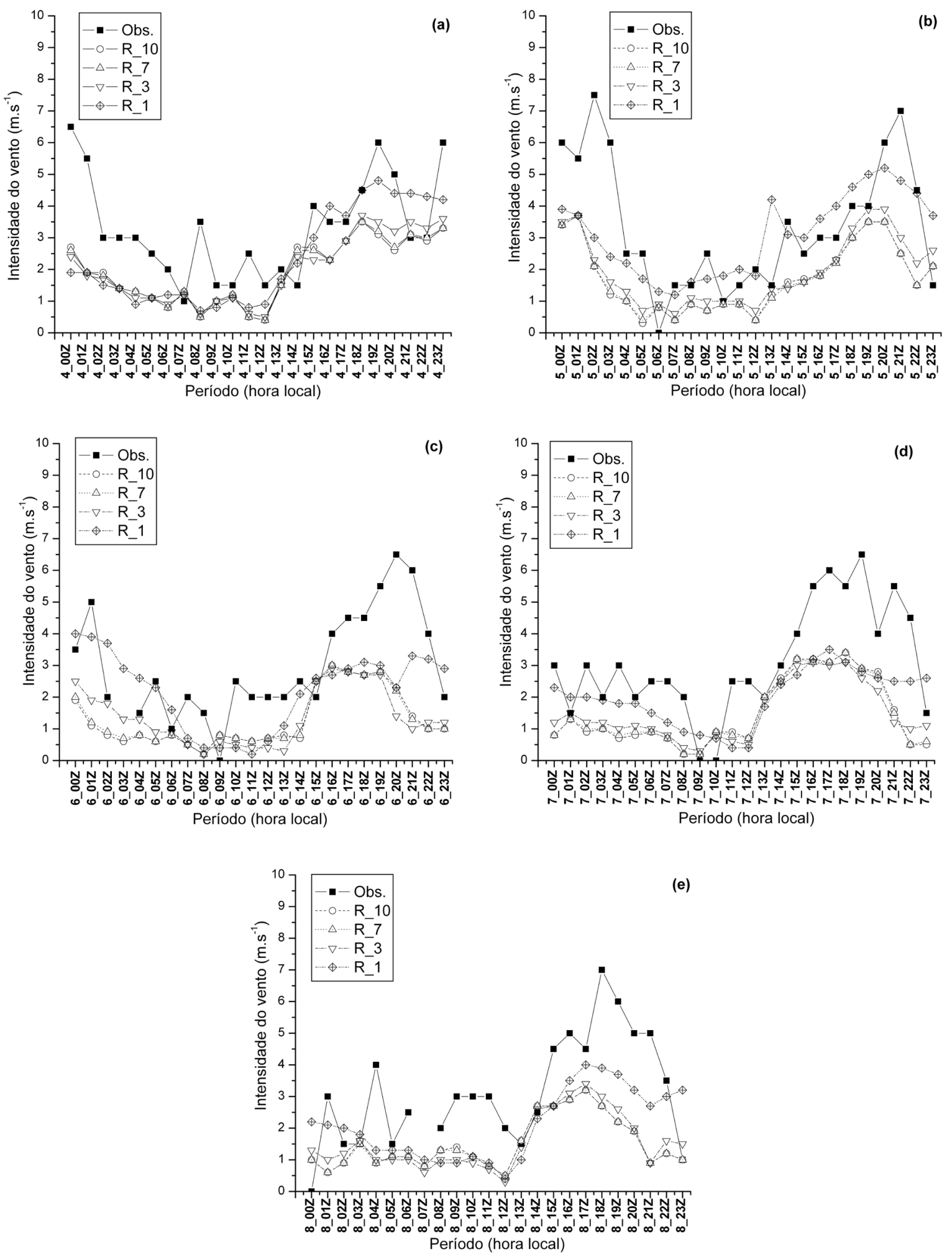

Figura 6 - Comparação entre intensidade do vento, simulada pelo modelo CALMET, utilizando valores de $1 \mathrm{~km}, 3 \mathrm{~km}, 7 \mathrm{~km}$ e $10 \mathrm{~km}$ para o parâmetro R, e dados observados da estação SBRJ para o período de 4 a 8 de setembro de 2007. 
de influência $R_{-}$l, verificou-se que a intensidade dos ventos é semelhante aos da estação SBRJ. Esse comportamento possivelmente contribuiu para a melhor representação da configuração $R \_1$ na simulação do campo de vento observado na estação SBRJ.

As simulações $R_{-} 3, R_{-} 7$ e $R_{-} 10$ apresentaram comportamentos semelhantes entre si e aos dados observados durante todo o período. No entanto, nota-se uma tendência de subestimativa do valor do vento observado em até $4 \mathrm{~m} / \mathrm{s}$. Deve-se destacar que os dados observados nas estações CTRF, NITE, MARA e LAGO registraram ventos durante o período da ordem de $1,5 \mathrm{~m} / \mathrm{s}$, notadamente inferiores aos registrados em SBRJ. Esse aspecto contribuiu para que as simulações com $R \_3, R \_7$ e $R \_10$ subestimassem a intensidade do vento na estação avaliada.

Na Figura 7 é apresentada a comparação da evolução da direção do vento observado com as simulações realizadas com diferentes valores do raio de influência. Os dados observados indicam um marcante padrão de brisa marítima/terrestre, principalmente nos dias $6-8$, com ventos predominantes norte-nordeste no período da tarde/noite e de sul no período da madrugada/manhã, concordando com o regime típico local. Os resultados para a simulação $R_{-} l$ não reproduziram adequadamente as direções do vento nos dois primeiros dias, onde o giro do vento para sul-sudeste não foi bem representado. As simulações com o CALMET para $R_{-} 3, R_{-} 7$ e $R_{-} 10$ apresentaram resultados concordantes entre si e capturaram o padrão de direção dos ventos no período analisado, inclusive representando satisfatoriamente os horários de giro norte-sul, ocorridos aproximadamente às $1200 \mathrm{Z}$. Os resultados dessas simulações foram influenciados pelos dados observados utilizados no Passo 2 (cálculo do campo de vento final), provenientes das demais estações meteorológicas de superfície na região.

A terceira e última localidade analisada na Bacia Aérea III é referente à estação SBGL, destacada na Figura 1. Destaca-se, inicialmente, que a análise referente à estação SBGL difere das demais por não possuir outras estações inseridas no raio de influência de $10 \mathrm{~km}\left(R_{-} 10\right)$, além dela própria. Essa característica influi diretamente no cálculo do campo de vento com o CALMET, onde para os menores raios de influência haverá maior contribuição dos resultados do modelo prognóstico (MM5) sobre o campo de vento final (Passo 2).

Devido a sua posição geográfica, a localidade SBGL está sujeita às brisas marítima e terrestre e também à brisa da própria baía, tornando difícil distinguir um regime de ventos predominante. Entretanto, alguns estudos realizados (Silva de Souza et al., 1996 e Pimentel et al., 2014) verificaram direções predominantes em períodos específicos do dia: ventos de norte no período da manhã, de sudeste no período tarde/noite e de leste durante a madrugada com a ocorrência dos principais registros de calmaria.

De acordo com a Figura 8, os dados observados destacam ventos mais intensos entre os horários $1800 \mathrm{Z}$ e 2200Z, quando estes atingem cerca de $9 \mathrm{~m} / \mathrm{s}$ nos dias 4 e 5 , e cerca de 6 a 7 $\mathrm{m} / \mathrm{s}$ nos demais dias. Esses valores máximos observados estão de acordo com os registros típicos de intensidade e horário apresentados na caracterização climatológica em Pimentel et al. (2014).

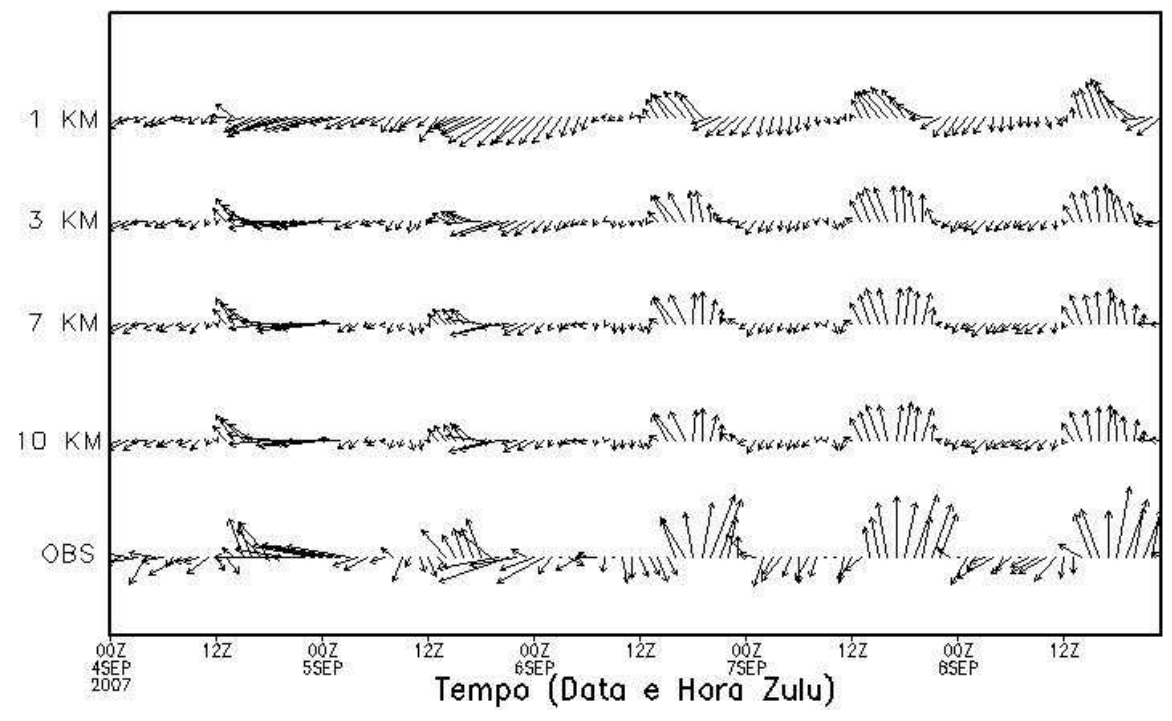

Figura 7 - Comparação entre a direção de vento, simulada pelo modelo CALMET, utilizando valores para R com 1 km (R_1), 3 km (R_3), 7 km (R_7) e 10 km (R_10), e dados observados da estação SBRJ para o período de 4 a 8 de setembro de 2007. 

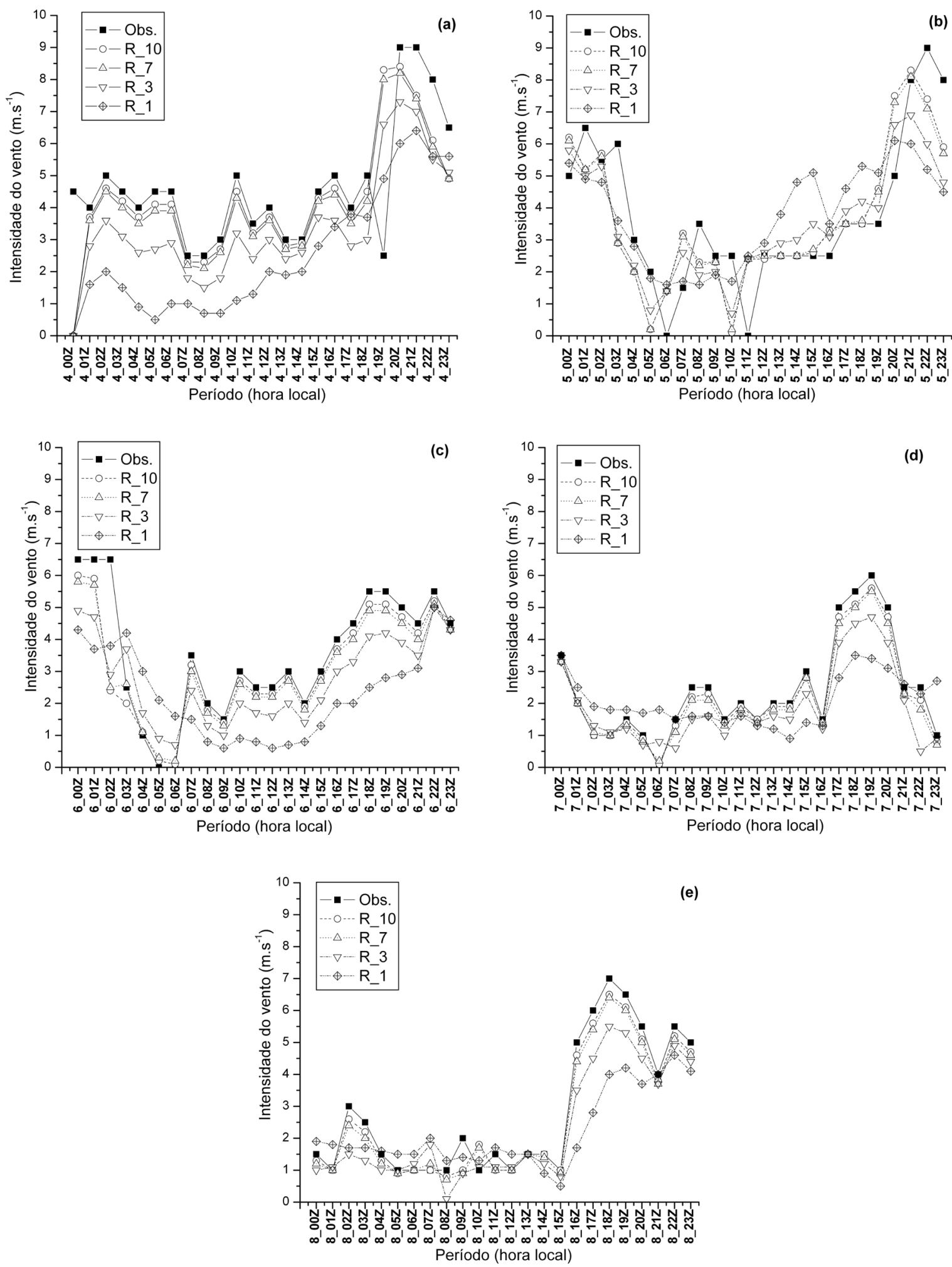

Figura 8 - Comparação entre intensidade do vento, simulada pelo modelo CALMET, utilizando valores para R com $1 \mathrm{~km}, 3 \mathrm{~km}, 7 \mathrm{~km}$ e $10 \mathrm{~km}$, e dados observados da estação SBGL para o período de 4 a 8 de setembro de 2007. 
Em relação às simulações, nota-se que as configurações $R_{-} 1$ e $R_{-} 3$ subestimaram as maiores intensidades em aproximadamente 2 a $3 \mathrm{~m} / \mathrm{s}$ e 1 a $2 \mathrm{~m} / \mathrm{s}$, respectivamente. Por outro lado, o comportamento do vento foi reproduzido com maior sucesso pelas configurações $R \_7$ e $R 10$. Essa observação está associada ao destacado anteriormente, em que para os menores raios de influência há maior contribuição dos resultados do modelo prognóstico (MM5), em detrimento dos dados observados, sobre o cálculo do campo de vento final (Passo 2).

A Figura 9 contém a comparação da direção observada dos ventos em SBGL com os resultados das simulações realizadas com diferentes valores de $R$. Observa-se que nos horários de maior intensidade do vento, a estação registra a direção de sudeste em todos os dias, principalmente no final da tarde e início da noite, concordando com o padrão típico identificado em Silva de Souza et al. (1996) e Pimentel et al. (2014). Nos demais períodos do dia, observa-se vento de baixa intensidade, com a ocorrência da direção nordeste aproximadamente às 1200Z. Esse comportamento do regime vento é bem representado com as configurações $R \_7 \mathrm{e}$ $R \_10$, em contraste com as simulações realizadas para $R_{-} 1$ e $R \_3$. A configuração $R_{-} l$ simulou um vento com direção predominantemente de norte e nordeste, não evidenciando o ciclo diário das brisas marítima e terrestre. Apesar da configuração R_3 apresentar um padrão de direção de vento fisicamente mais consistente que $\mathrm{R}_{-}$, este ainda evidencia discrepâncias em relação aos dados medidos na SBGL. As configurações $R \quad 7$ e $R \quad 10$ simularam direções concordantes com os registros na SBGL, inclusive representando adequadamente os horários de giro do vento no ciclo diário. À semelhança do que ocorreu com a intensidade do vento (Figura 8 ), verifica-se que as direções simuladas pela $R_{-} l$ foram fortemente influenciadas pelas direções obtidas nas simulações com o modelo MM5 para esta estação. Em contrapartida, nas configurações $R \quad 7$ e $R \quad 10$ destaca-se um maior sucesso em simular as direções do vento observado em virtude do maior peso atribuído aos dados das estações de superfície, conforme o aumento do raio de influência.

\subsection{Verificação do efeito dos dados observados sobre o campo de vento do modelo CALMET para a estação SBSC}

A seguir, é realizada a verificação dos resultados das simulações para regiões onde não são disponibilizados dados meteorológicos. O procedimento definido para o desenvolvimento dessa análise foi a não inserção dos dados meteorológicos da estação SBSC, considerando simulações com a configuração $R \_10$, e posterior comparação dos resultados com esses dados.

A Figura 10 contém os resultados das simulações realizadas com os modelos CALMET (sem inserção de dados da SBSC) e MM5 comparados com os dados observados da estação SBSC. Verificou-se que os modelos MM5 e CALMET não apresentaram resultados concordantes com as observações, com discrepâncias mais acentuadas e uma sistemática tendência do CALMET em subestimar em até $4 \mathrm{~m} / \mathrm{s}$ a intensidade do vento durante todo o período na SBGL. Os resultados obtidos com o modelo MM5 e CALMET, apresentados na Figura 11 , não representaram adequadamente o ciclo diário do

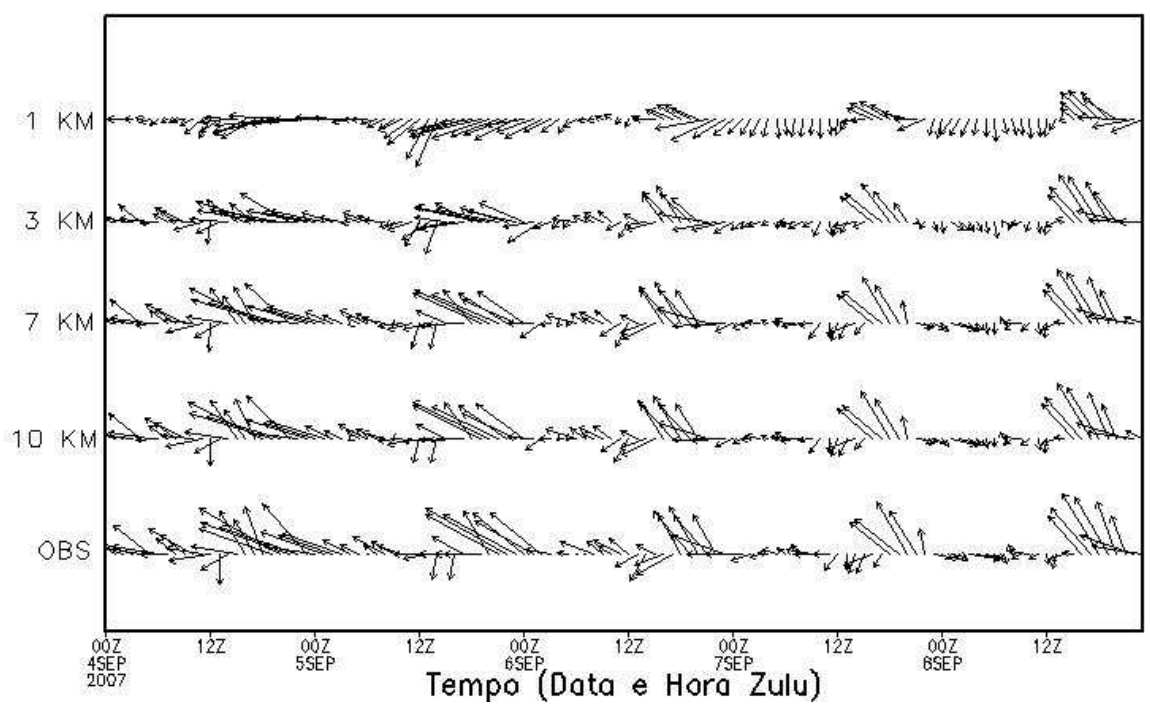

Figura 9 - Comparação entre a direção de vento, simulada pelo modelo CALMET, utilizando valores para R com $1 \mathrm{~km}\left(\mathrm{R} \_1\right), 3 \mathrm{~km}\left(\mathrm{R} \_3\right), 7 \mathrm{~km}$ (R 7) e 10 km (R 10), e dados observados da estação SBGL para o período de 4 a 8 de setembro de 2007. 

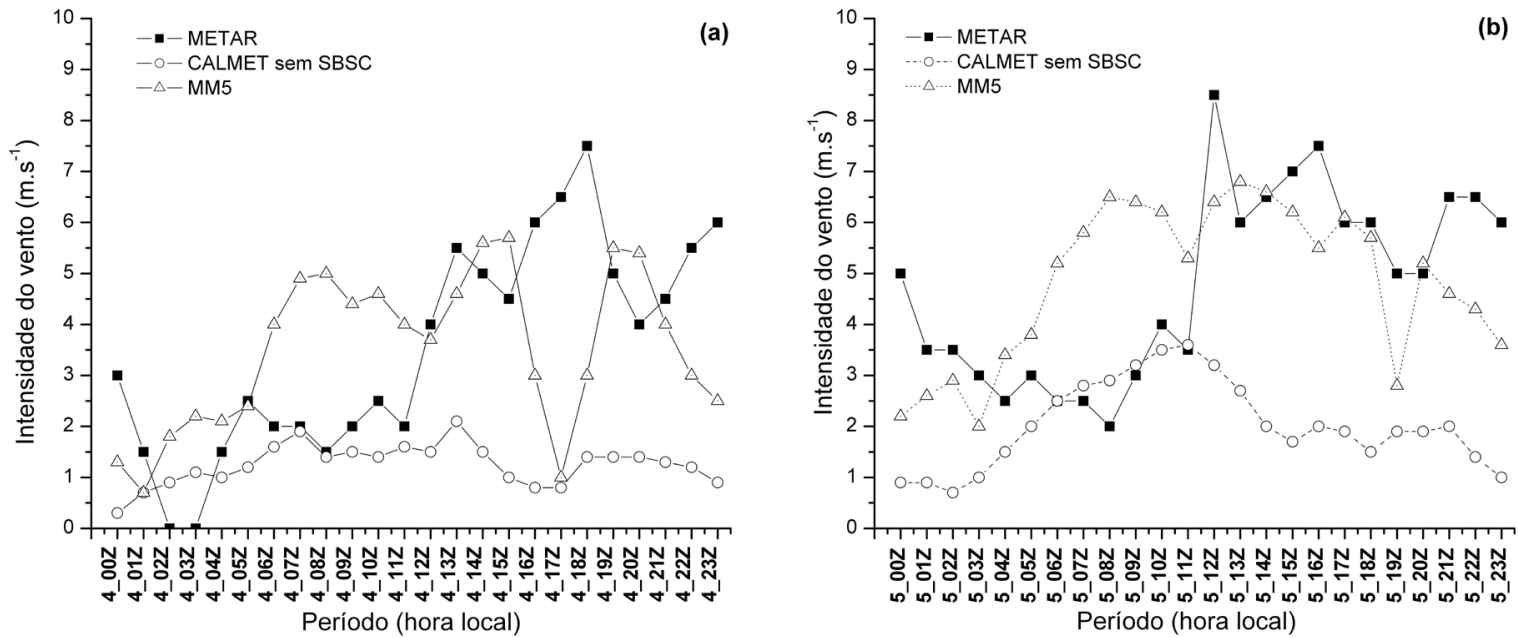

का Período (hora local)
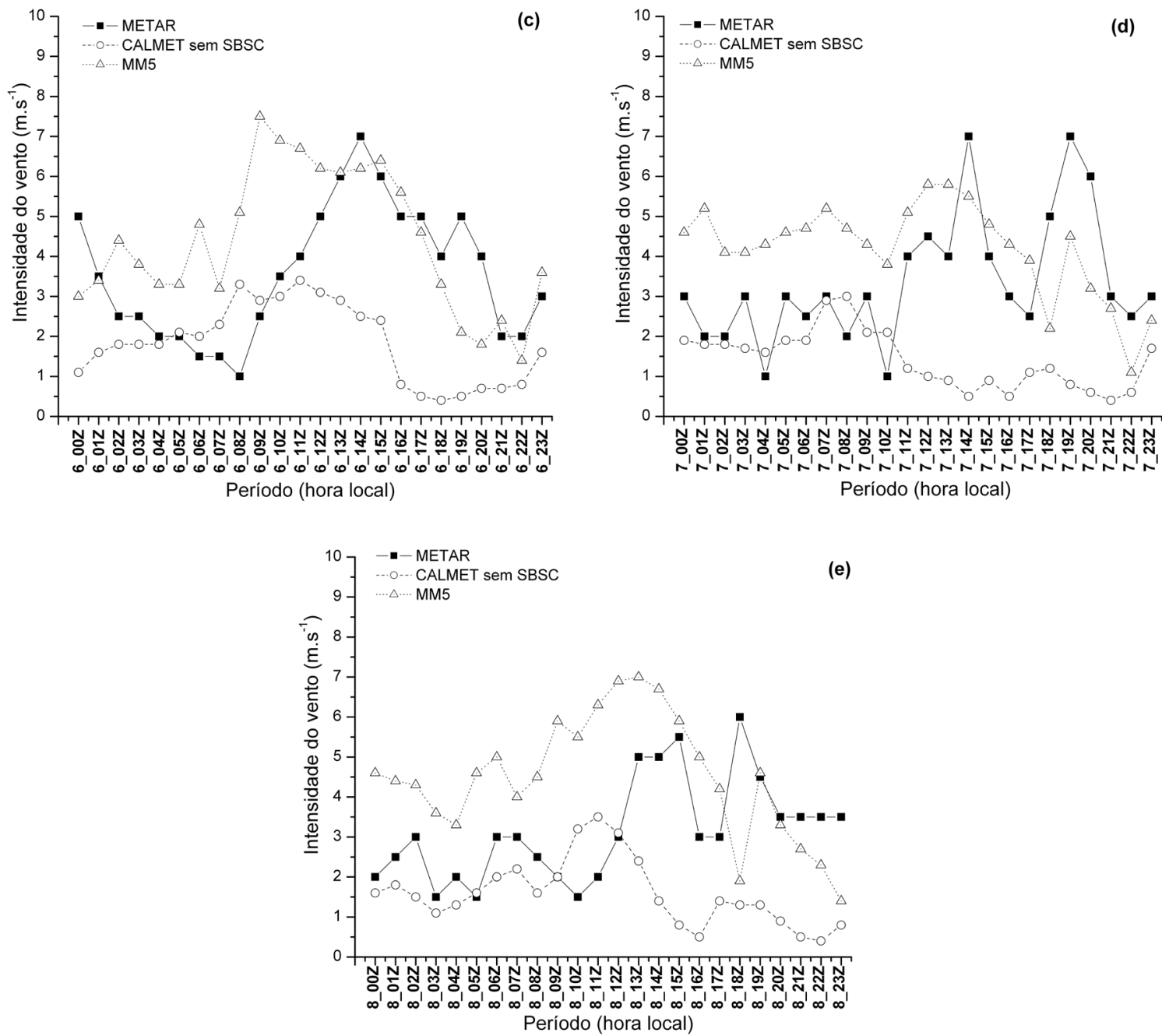

Figura 10 - Comparação entre intensidade do vento, simulada pelo modelo MM5 e pelo modelo CALMET (configuração R 10) sem a assimilação dos dados medidos na estação SBSC, e os dados observados da estação SBSC para o período de 4 a 8 de setembro de 2007. 


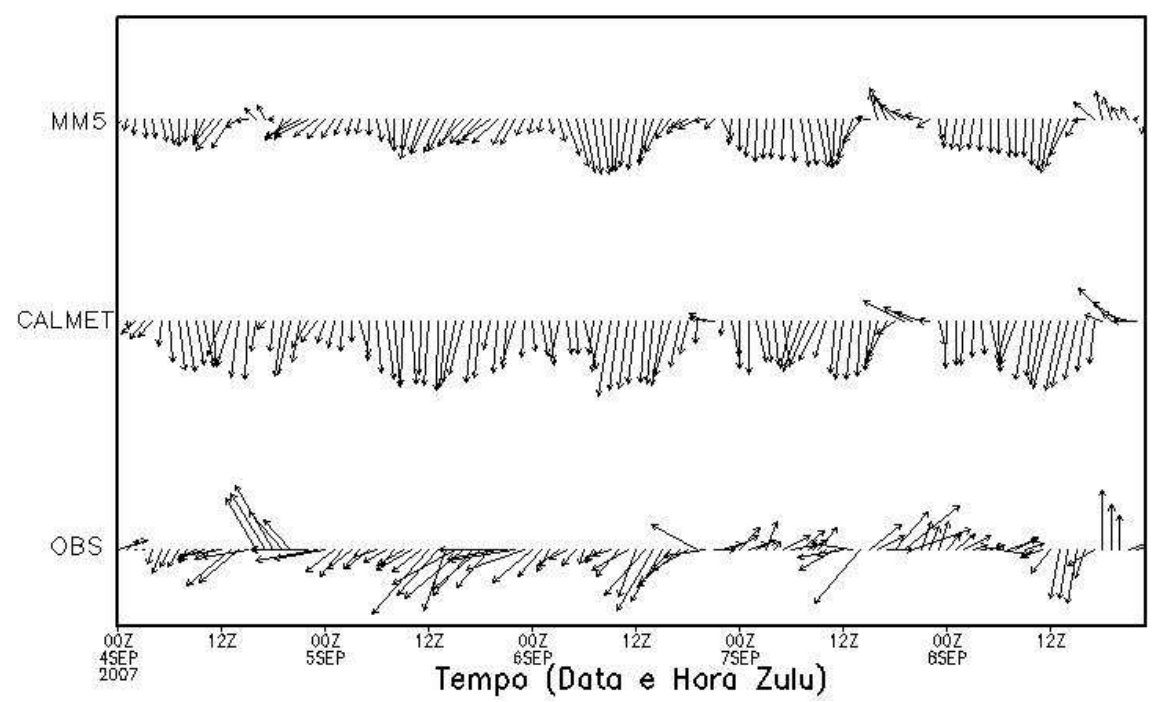

Figura 11 - Comparação entre direções de vento, simuladas pelos modelos MM5 e CALMET (configuração R_10) sem assimilação de dados observados da estação SBSC para o período de 4 a 8 de setembro de 2007.

vento verificado com os dados observados, onde os modelos simularam principalmente a direção norte durante quase todo o período, com exceção de alguns horários no final da tarde dos dias 6,7 e 8 . As simulações indicaram pouca habilidade dos modelos em capturar o ciclo sudoeste/nordeste da brisa marítima/terrestre naquela região, influenciado pela Baía de Sepetiba e a orientação noroeste/sudeste do contorno da linha de costa, como identificado na caracterização climatológica em Pimentel et al. (2014). O comportamento do vento do modelo CALMET evidencia a drástica influência dos resultados do MM5 para o campo de vento no Passo 1 e, portanto, a inserção de dados observados e a adequada escolha dos valores do raio de influência, tornam-se indispensáveis para a construção do campo de vento final.

\section{CONCLUSÕES}

Neste trabalho foram realizadas simulações com o objetivo de avaliar o desempenho conjunto dos modelos MM5 e CALMET, e obter maior compreensão dos mecanismos forçantes das circulações que ocorrem na RMRJ sob o efeito da topografia e das circulações locais que atuam na região.

A partir de testes de sensibilidade, verificou-se que a maior concordância entre os resultados das simulações com o CALMET e os dados observados das estações meteorológicas, localizadas na RMRJ, foi para o valor de $10 \mathrm{~km}$ para o parâmetro TERRAD.

De um modo geral, a análise dos resultados obtidos com as configurações $R \_1, R \_3, R_{-} 7$ e $R \_10$ mostrou que as simulações utilizando os raios de influência com $7 \mathrm{~km}$ e $10 \mathrm{~km}$ apresentaram maior concordância com os dados medidos. Os resultados mostraram que o método de interpolação, utilizado pelo modelo CALMET, atribui pesos semelhantes aos dados simulados e aos dados observados quando se utiliza raios de pequeno alcance, o que explica o baixo rendimento da configuração $R_{-}$, influenciada pelos resultados do campo de vento inicial obtidos com as simulações do modelo MM5. Entretanto, se existirem estações próximas, cujos dados possam ser utilizados atribuindo maior peso às observações, essa configuração obtém melhores resultados, como comprovado para a estação SBRJ.

Os resultados apresentados, para simulações sem inserção dos dados meteorológicos da estação SBSC no modelo CALMET, indicaram para essa configuração a forte influência dos resultados do modelo prognóstico MM5 sobre o campo de vento final do modelo CALMET. O que evidencia a necessidade contínua da adequação dos modelos de mesoescala para a representação dos processos dinâmicos e termodinâmicos representativos da região de estudo.

A RMRJ possui um numero limitado de estações distribuídas de maneira desigual, o que dificulta a utilização de um raio de influência de pequeno alcance. De acordo com o presente estudo, recomenda-se para a região adotar um raio de influência de maior abrangência, atribuindo maior peso às observações nas áreas em torno das estações, de modo que as simulações realizadas com o modelo CALMET sejam moduladas pelos dados observados. Deve-se destacar que a definição desses raios de influência está sujeita às características locais da região de estudo, principalmente em relação a não homogeneidade do terreno. 


\section{BIBLIOGRAFIA}

ARNDT, R.L., CARMICHAEL, G.R.; ROORDA, M. J., "Seasonal Source-Recepton Relationships in Asia", Atmospheric Environment, v.32, n. 8, p. 1397-1406, 1998.

BARNA, M.; LAMB, B., Improving Ozone Modeling in Regions of Complex Terrain Using Observational Nuding in a Prognostic Meteorological Model. Atmospheric Environment, v.34, p. 4889-4906, 2000

BARNA, M., LAMB, B., O'NEAL, S., WESTBERG, H., FIGUEROA-KAMINSKY, C., OTTERSON, S., BOWMAN, C., DeMAY, J. Modeling Ozone Formation and Transport in the Cascadia Region of the Pacific Northwest. Journal of Applied Meteorology, v.39, p.349-366, 2000

BASTOS, C.; FERREIRA, N. Análise Climatológica da Alta Subtropical do Atlântico Sul. In: XI Congresso Brasileiro de Meteorologia. Anais do XI Congresso Brasileiro de Meteorologia. Rio de Janeiro, p. 612-619, 2000.

CARVAlHO, V. S. B.. Avaliação da Concentração do Poluente Ozônio e de seus Precursores na RMRJ e Correlação deste com Variáveis Meteorológicas. 2004. $150 \mathrm{f}$ Monografia (Bacharelado em Meteorologia), Universidade Federal do Rio de Janeiro, Rio de Janeiro,

CHANDRASEKAR, A., PHILBRICKB, C. R., CLARKC, R., Evaluating the Performance of a Computationally Efficient MM5/CALMET System for Developing Wind Field Inputs to Air Quality Models, Atmospheric Environment, v. 37, p 3267-3276, 2003.

CHEN, F.; DUDHIA, J., Coupling an Advanced Land-Surface/ Hidrology Model with the Penn State/NCAR MM5 Modeling System. Part I: Model Implementation and Sensitivity, Monthly Weather Review, v.129. p 569-585, 2000.

DOUGLAS, S.; KESSLER, R., User's Guide to the Diagnostic Wind Field Model (Version 1.0). Systems Applications, Inc., San Rafael, CA, p. 48, 1988

DUDHIA, J., 1989, Numerical Study of Convection Observed During the Winter Monsoon Experiment Using a Mesoscale Two-Dimensional Model. Journal of the Atmospheric Sciences, v. 46, pp. 3077-3107, 2008

EARTH TECH, Meteorological evaluation of the New Plymouth region using MM5 and CALMET for the period January to June 2005, relatório elaborado por Earth Tech Inc, Concord, MA, USA para The Foundation for Research Science and Technology, New Zealand, Research Programme: "Protecting New Zealand's Clean Air", p 73, 2005

GRELL, G., Prognostic evaluation of assumptions used by cumulus parameterizations. Monthly Weather Review, v. 121, p. 764, 1993.
GRELL, G. A., DUDHIA, J., STAUFFER, D. R., “A description of the Fifth-Generation Penn State/ NCAR Mesoscale Model (MM5)." NCAR Technical Note, NCAR/TN-398+STR, pp. 117, 1995.

JACKSON, B., D. CHAU, K. GURER., A. KADUWELA, Comparison of ozone simulations using MM5 and CALMET/ MM5 hybrid meteorological fields for the July/ August 2000 CCOS episode. Atmospheric Environment, v. 40, p.2812-2822. 2006.

O'BRIEN, J.J., A Note on the Vertical Structure of the eddy Exchange Coefficient in the Planetary Boundary Layer, Journal of the Atmospheric Sciences, v. 27, p. 12131215,1970

MELLOR, G. L., YAMADA, T. A Hierarchy of turbulence closure models for planetary boundary layers, Journal of the Atmospheric Sciences, v.13, p.1791-1806, 1974.

PIMENTEL, L.C.G., MARTON, E., SOARES DA SILVA, M. JOUDAN, P., Caracterização do regime de vento em superfície na Região Metropolitana do Rio de Janeiro. Engenharia Sanitaria Ambiental, v.19, p. 121-132, 2014.

PRIETO, M., NAVARRO, J., COPELAND, J., A Comparison of Wind Field Simulations Through a Coupling of MM5/ CALMET in a Complex Terrain. In: EUROPEAN WIND ENERGY CONFERENCE, 2007, Milan, Italy.

REBOITA, M. S.;GAN, M. A.; ROCHA, R.P.;AMBRIZZI, T. Regimes de precipitação na América do Sul: uma revisão bibliográfica. Revista Brasileira de Meteorologia, v.25, p.185-204, 2010.

SCIRE, J.S., ROBE, F.R., FERNAU, M.E., YARMATINO, R.J. A User's Guide for the CALMET Meteorological Model (Version 5). 2000, Earth Tech Inc., Concord, MA, p.316.

SILVA DE SOUZA, L. S., CARVALHO, D. D., SEABRA, M. S., RIBEIRO, M. L., GONÇALVES, I. F. S., Um Enfoque Climatológico das Relações entre Precipitação Pluviométrica e Vento na Região Metropolitana do Rio de Janeiro. In: Congresso Brasileiro de Meteorologia, 1996.

USEPA, Science Algorithms of the EPA Models-3 Community Multiscale Air Quality (CMAQ) Modeling System. In: U.S. ENVIRONMENTAL PROTECTION AGENCY. EPA600/R-99/030; U.S.Government Printing Printing Office: Washington, DC, 1999.

YAMARTINO, R.J., SCIRE, J.S., HANNA, S.R., CARMICHAEL, G.R., CHANG, Y.S., The calgrid, a mesoscale photochemical grid model, volume I - Model Formulation, Atmospheric Environment, v. 26A, p. 14931512, 1992.

YIM, S.H.L.; FUNG, J.C.H.; LAU, A.K.H.; KOT, S.C. Developing a high-resolution wind map for a complex terrain with a coupled MM5/CALMET system. Journal of Geophysical Research, v.112, p.15, 2007. 
WANG W., SHAW W. J., SEIPLE T. E., RISHEL J. P., XIE Y., An evaluation of a diagnostic wind model (Calmet), Journal of Applied Meteorology and Climatology, v. 47, p. 1739-1756, 2008.
WHITEMAN, C. D., DORAN, J. C. "The Relationship bet ween Overlying Synoptic-Scale Flows and Winds within a Valley". Journal Applied Meteorology, v.32, p.1669-1682, 1993. 